\title{
BMJ Open Impact of the pretransplant dialysis modality on kidney transplantation outcomes: a nationwide cohort study
}

\author{
Huan-Tang Lin, ${ }^{1,2}$ Fu-Chao Liu, ${ }^{1,2}$ Jr-Rung Lin, ${ }^{1,2,3}$ See-Tong Pang, ${ }^{2,4}$ \\ Huang-Ping $\mathrm{Yu}^{1,2,5}$
}

To cite: Lin H-T, Liu F-C, Lin J-R, et al. Impact of the pretransplant dialysis modality on kidney transplantation outcomes: a nationwide cohort study. BMJ Open 2018;8:e020558. doi:10.1136/ bmjopen-2017-020558

- Prepublication history for this paper is available online. To view these files, please visit the journal online (http://dx.doi. org/10.1136/bmjopen-2017020558).

$\mathrm{H}-\mathrm{TL}$ and F-CL contributed equally.

Received 9 November 2017

Revised 29 March 2018

Accepted 11 May 2018

Check for updates

${ }^{1}$ Department of Anesthesiology, Chang Gung Memorial Hospital, Taoyuan, Taiwan

${ }^{2}$ College of Medicine, Chang

Gung University, Taoyuan,

Taiwan

${ }^{3}$ Clinical Informatics and Medical Statistics Research Center, Graduate Institute of Clinical Medicine, Chang Gung University, Taoyuan, Taiwan

${ }^{4}$ Department of Urology, Chang Gung Memorial Hospital,

Taoyuan, Taiwan

${ }^{5}$ Department of Anesthesiology, Xiamen Changgung Hospital, Taoyuan, Taiwan

Correspondence to

Dr Huang-Ping Yu;

yuhp2001@adm.cgmh.org.tw

\section{ABSTRACT}

Objective Most patients with uraemia must undergo chronic dialysis while awaiting kidney transplantation; however, the role of the pretransplant dialysis modality on the outcomes of kidney transplantation remains obscure. The objective of this study was to clarify the associations between the pretransplant dialysis modality, namely haemodialysis $(\mathrm{HD})$ or peritoneal dialysis $(\mathrm{PD})$, and the development of post-transplant de novo diseases, allograft failure and all-cause mortality for kidney-transplant recipients.

Design Retrospective nationwide cohort study.

Setting Data retrieved from the Taiwan National Health Insurance Research Database.

Participants The National Health Insurance database was explored for patients who received kidney transplantation in Taiwan during 1998-2011 and underwent dialysis $>90$ days before transplantation.

Outcome measures The pretransplant characteristics, complications during kidney transplantation and posttransplant outcomes were statistically analysed and compared between the HD and PD groups. Cox regression analysis was used to evaluate the HR of the dialysis modality on graft failure and all-cause mortality. The primary outcomes were long-term post-transplant deathcensored allograft failure and all-cause mortality started after 90 days of kidney transplantation until the end of follow-up. The secondary outcomes were events during kidney transplantation and post-transplant de novo diseases adjusted by propensity score in log-binomial model. Results There were 1812 patients included in our cohort, among which 1209 (66.7\%) and 603 (33.3\%) recipients received pretransplant $\mathrm{HD}$ and $\mathrm{PD}$, respectively. Recipients with chronic HD were generally older and male, had higher risks of developing post-transplant de novo ischaemic heart disease, tuberculosis and hepatitis $\mathrm{C}$ after adjustment. Pretransplant HD contributed to higher graft failure in the multivariate analysis (HR 1.38, $p<0.05$ ) after adjustment for the recipient age, sex, duration of dialysis and pretransplant diseases. There was no significant between-group difference in overall survival.

Conclusions Pretransplant HD contributed to higher risks of death-censored allograft failure after kidney transplantation when compared with PD.

\section{INTRODUCTION}

Kidney transplantation is the preferable and definite therapy for patients with end-stage

\section{Strengths and limitations of this study}

This is the first nationwide population-based cohort study to demonstrate that pretransplant haemodialysis contributed to higher risks of allograft failure after kidney transplantation when compared with peritoneal dialysis.

- The nationwide database covers more than $99 \%$ of the Taiwanese population.

- Our study had a relatively large number of recipients and a long follow-up duration compared with other studies.

- Because of the lack of clinical data on graft function and laboratory results, we could not determine the mechanism of graft failure.

renal disease (ESRD), offering substantial benefits in terms of healthcare costs, life expectancy and quality of life. ${ }^{12}$ However, kidney transplantation is often not accessible due to organ shortage, and most patients with ESRD must undergo renal replacement therapy such as haemodialysis (HD) or peritoneal dialysis (PD) while awaiting a donor kidney. HD is the most commonly used dialysis modality worldwide, with at least $80 \%$ of chronic dialysis patients receiving in-centre HD in three-fourths of reporting countries in 2014. ${ }^{3}$ Meanwhile, PD seems to be underused in most countries; in 2014, only $9.5 \%$ of dialysis patients used this modality in the USA. ${ }^{145}$ The estimated life expectancy of patients with ESRD receiving HD or PD are nearly equal (19.11 vs 19.08 years). However, PD is more cost-effective than HD after considering the quality of life, dialysis costs and its associated complications. ${ }^{6}$ Thus, the promotion of a PD-first policy has modestly increased the overall trends of PD use in chronic dialysis patients in the USA and other countries since $2006 .^{7}$

Although the short-term outcomes of kidney transplantation have significantly improved over the past three decades, owing to modern 
medical care and immunosuppression, the long-term graft survival has shown minimal improvement. ${ }^{8}$ This discrepancy is often attributed to the increasing use of expanded-criteria donor kidneys, the ageing of the recipient population, alloantibody-mediated graft injury and recurrent glomerular pathologies. ${ }^{9} 10$ The long-term outcomes of kidney transplantation are determined by factors relating to the donor, graft function, recipient and immunosuppression. ${ }^{8}$ Among these intricate characteristics, the dialysis modality seems to be the most readily modifiable factor. Previous studies have reported inconsistent results regarding the effect of the pretransplant dialysis modality on the outcomes of kidney transplantation. A cohort study of simultaneous pancreas-kidney transplantation for patients with type 1 diabetes showed an association between the use of PD and worse outcomes secondary to increased incidences of graft thrombosis, new-onset diabetes after transplantation and intra-abdominal infection, thus leading to worse patient survival. ${ }^{11}$ In contrast, other studies have found better kidney transplantation outcomes in patients receiving $\mathrm{PD}$, including lower incidences of delayed graft function (DGF), shorter pretransplant dialysis duration and better long-term patient survival. ${ }^{12} 13$ These conflicting results might originate from factors other than the dialysis modality, such as different donor characteristics, follow-up durations and the methodological design of these studies (ie, registry-based or single-centre studies). ${ }^{14}$

Taiwan had the highest prevalence and incidence of ESRD and dialysis in the world since $2000,{ }^{3}$ but convincing evidence-based studies regarding suggested dialysis modality for patients with ESRD awaiting kidney transplantation were scarce, especially in Asian population. Therefore, we conducted this nationwide cohort study based on the National Health Insurance (NHI) database of Taiwan to compare the clinicodemographic characteristics, post-transplant de novo diseases and kidney transplantation outcomes between the different dialysis modalities.

\section{PATIENTS AND METHODS \\ Data collection}

We conducted a retrospective nationwide cohort study based on Taiwan's NHI database. This database routinely collects health information from all NHI beneficiaries in Taiwan since 1995. The NHI is a single medical expense payer system that covered over $99.6 \%$ of registered beneficiaries in the NHI database at the end of 2014. Deidentified and computerised data were provided by the Bureau of NHI, which organises claimed data for the entire NHI system and has established the NHI research database. Basic patient information and medical data are encrypted and encoded using the International Classification of Diseases, Ninth Revision, Clinical Modification (ICD-9) codes in our included NHI database during 1997-2013. The validity, representativeness and clinical consistency of this database have been reported in many previous studies. $^{15}$
The present study conformed to the Declaration of Helsinki of 1975, as revised in 2000. As the data used in this study were anonymised, the need for patient consent was waived.

\section{Patient selection}

The eligible population comprised 23462863 beneficiaries registered in the NHI database in 2013. The total studied NHI database spanned from 1997 to 2013, but to ensure data integrity and adequate follow-up periods, we included kidney recipients in Taiwan between 1998 and 2011 for further analysis. We identified patients receiving kidney transplantation in Taiwan in the NHI databases using the ICD-9 diagnosis code of kidney transplant status (V42.0) and operation codes of kidney transplantation (55.6, 76020A, 76020B and 97416K). In order to examine long-term post-transplant outcomes between patients receiving pretransplant chronic $\mathrm{HD}$ and $\mathrm{PD}$, we excluded patients who did not meet with our requirements such as dialysis less than 90 days, unconfirmed dialysis modality and uncertain dialysis duration.

\section{Measurements}

The clinicodemographic characteristics of the kidney-transplant recipients with HD or PD were identified and compared, including their age, sex, residence area, income level, dialysis duration, Charlson Comorbidity Index (CCI) score, pretransplant diseases, events during kidney transplantation, post-transplant de novo diseases and kidney transplantation outcomes. Only patients with the preoperative disease codes identified in the NHI database between 1998 and 2011 at least once in the inpatient setting or $>3$ times in outpatient visits were included. The CCI score, which comprises 17 diagnostic criteria, was used to evaluate the patients' medical burden before kidney transplantation. The analysed disease with accompanied ICD-9 code for between-group comparison were as follows: hypertension (401-405), diabetes (250), ischaemic heart disease (410-414), heart failure (428), stroke (430-438), liver cirrhosis (571-572), malignancy (140-208) and hepatitis C (070.4). The recorded events with accompanied ICD-9 code during hospitalisation for kidney transplantation were dialysis events, vascular thrombosis $(444,453)$, and infection episodes (including bacteraemia (790.7), peritonitis (567), pneumonia (480486) and urinary tract infection (UTI) (599.0)). Post-transplant de novo diseases were defined as new-onset diseases recorded during our follow-up period started after 90 days of kidney transplantation until the end of follow-up or patient death. The analysed de novo diseases include hypertension, ischaemic heart disease, peripheral arterial occlusive disease (440), psychiatric disease $(300,301)$, tuberculosis (010018), malignancy, chronic obstructive pulmonary disease (490-496), liver cirrhosis, herpes zoster (053), hepatitis B (070.3) and hepatitis C.

\section{Patients and public involvement}

No patients or public were involved in setting out the research question or developing the outcome measures, 
nor were they involved in developing plans for design or implementation of the study. No patients or public were asked to advise on interpretation or writing up of results, nor was the burden of the interventions on patients assessed. The results of the research will be disseminated to those study participants who wished to be notified of them.

\section{Statistical analysis}

The primary outcomes in our study were long-term post-transplant allograft failure and all-cause mortality during our follow-up period started after 90 days of kidney transplantation until the end of follow-up. We defined allograft failure as return to chronic dialysis ( $>90$ days) after kidney transplantation or as receiving another kidney transplantation. Because allograft failure and death act as competing events after kidney transplantation, we applied the concept of competing-risk framework and used death-censored allograft failure as our measured outcome in the Cox proportional hazard model. ${ }^{1617}$ On the other hand, since the true cause of death was unavailable in our NHI database, all-cause mortality was chose as another primary outcome and was defined as detection of death codes or termination of NHI. Because recipients with pretransplant HD or PD had different characteristics, significant pretransplant recipient factors (including recipient sex, age, dialysis duration and pretransplant diseases (diabetes, stroke and heart failure)) were selected to adjust death-censored graft failure and all-cause mortality in multivariate analyses. Subsequently, survival curves of pretransplant dialysis modality on kidney transplantation outcomes based on the Cox proportional hazard model were plotted and the between-group differences were compared.

The secondary outcomes were events during kidney transplantation and post-transplant de novo diseases during follow-up period started after 90 days of kidney transplantation until the end of follow-up or patient death. Because different characteristics between recipients with pretransplant $\mathrm{HD}$ and pretransplant $\mathrm{PD}$, we applied propensity score covariate adjustment in log-binomial regression model to calculate relative risks (RR) for the secondary outcomes. ${ }^{18} 19$ The propensity score covariates used for adjustment were selected from significant pretransplant factors and were the same as these used in multivariate analyses (ie, recipient sex, age, dialysis duration and pretransplant diseases (diabetes, stroke and heart failure)). Sensitivity analysis of the propensity score model was assessed by calculating the c-statistic, which showed good discrimination in adjusting potential confounding associated with the choice of dialysis modality. ${ }^{20}$

All statistical analyses were conducted using SAS software (V.9.4; SAS Institute), with $\mathrm{p}<0.05$ considered statistically significant.

\section{RESULTS}

Clinical characteristics of kidney-transplant recipients with different dialysis modalities

Figure 1 shows a flow chart of the patient selection and identification programme in our study. There were 2741 patients receiving kidney transplantation in Taiwan between 1998 and 2011. Then we excluded 359 patients who did not receive chronic dialysis before kidney transplantation (dialysis $<90$ days or $<5$ times), and 126 patients who had a non-specific dialysis modality (concomitant use or transition from one to the other). To ensure accurate estimation of the dialysis duration, we also excluded 420 patients who had dialysis records before 31 March 1997. Finally, since the primary outcome of allograft failure in our study was defined as re-entry of chronic dialysis $>90$ days after kidney transplantation or retransplantation, we excluded 24 patients from our cohort because they died within 90 days of kidney transplantation (17 and 7 patients in the HD and PD groups, respectively) thus hampered the observation. The final cohort consisted of 1812 recipients of kidney transplantation during 1998-2011, among which $1209(67 \%)$ and $603(33 \%)$ patients had undergone pretransplant chronic HD and PD, respectively. Table 1 lists the comparison of clinical characteristics between kidney-transplant recipients with chronic $\mathrm{HD}$ and with chronic PD. The median(Q1-Q3) follow-up duration was 6.06 (3.84-8.92) years, and follow-up durations were similar in both groups. Patients with chronic HD were older (44.79 \pm 11.57 vs $38.28 \pm 13.45$ years) and more frequently male. Analysis of the age distribution showed that more young patients $(<18$ years) in the PD group and more old patients ( $>65$ years) in the HD group. There was no obvious difference in the geographical distribution between the different dialysis groups, except significantly more recipients in southern Taiwan choosing HD. There were more recipients with a low-income level choosing PD (quintiles 1 and 2: $57.04 \%$ in PD vs $54.68 \%$ in HD). Recipients with HD had higher CCI scores $(2.54 \pm 0.87$ in $\mathrm{HD}$ vs $2.38 \pm 0.63$ in PD, $\mathrm{p}<0.05)$ and longer pretransplant dialysis durations $(3.33$ (1.58-5.64) years in HD vs 2.67 (1.32-4.33) years in PD, $\mathrm{p}<0.05)$. Regarding the pretransplant comorbidities in the different dialysis modality groups, recipients with HD had significant higher incidences of diabetes, ischaemic heart disease, heart failure, stroke and hepatitis C. As for our primary outcomes, the cumulative incidences of allograft failure during 1998-2011 were significantly higher in recipients with HD compared with the PD group (15.63\% in HD vs $11.44 \%$ in $\mathrm{PD}, \mathrm{p}<0.05)$, whereas there was no significant difference in cumulative incidences of all-cause mortality ( $11.41 \%$ in $\mathrm{HD}$ vs $8.96 \%$ in $\mathrm{PD}, \mathrm{p}=0.109)$.

\section{Adverse events during hospitalisation for kidney transplantation}

Table 2 shows the impact of the different dialysis modalities on the events during hospitalisation for kidney transplantation after propensity score adjustment. Recipients with chronic PD had significantly higher infection risks in peritonitis (RR of HD over PD $0.15,95 \%$ CI 0.04 to $0.58, \mathrm{p}<0.05$ ) 


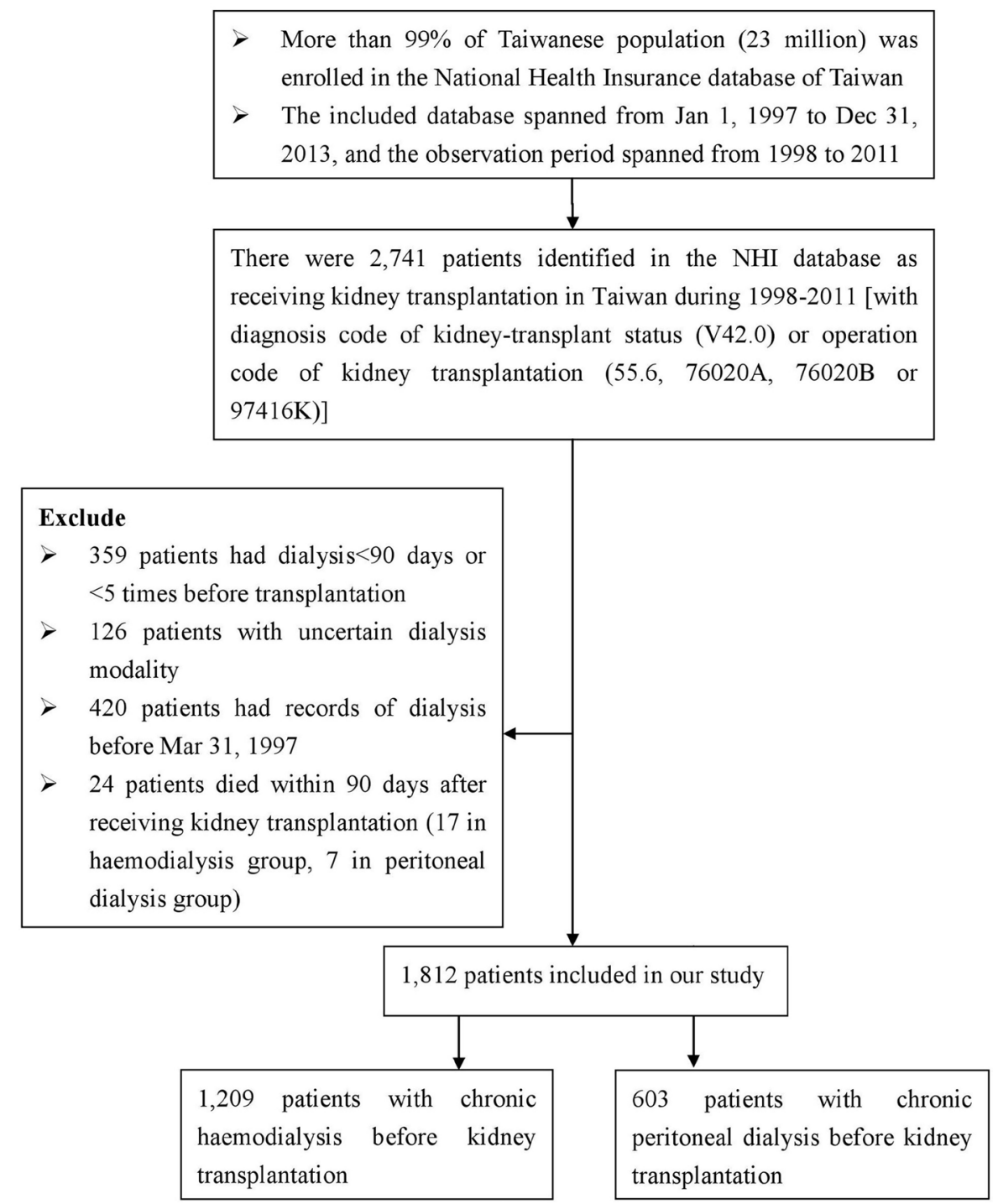

Figure 1 Study design and flow chart of the patient selection. NHI, National Health Insurance.

and UTI (RR of HD over PD $0.66,95 \%$ CI 0.45 to 0.96 , $\mathrm{p}<0.05)$ compared with patients with HD. Regarding the risks of vascular thrombosis, there was no significant differences after propensity score adjustment. On the contrary, recipients with $\mathrm{HD}$ experienced more dialysis events during kidney transplantation after adjustment ( 1.59 in $\mathrm{HD}$ vs 0.71 in $\mathrm{PD}, \mathrm{p}<0.05)$. There was no significant between-group difference in hospitalisation duration for kidney transplantation after adjustment (18.19 days in HD vs 18.15 days in PD, $\mathrm{p}=0.951$ ).

\section{New-onset diseases during follow-up period after $\mathbf{9 0}$ days of kidney transplantation}

As seen in table 3, compared with patients with PD, recipients with chronic HD had significantly higher risks of developing post-transplant de novo diseases after propensity score adjustment including ischaemic heart disease (RR 2.40, 95\% CI 1.21 to $4.77, \mathrm{p}<0.05$ ), tuberculosis (RR $10.23,95 \%$ CI 1.35 to $77.47, \mathrm{p}<0.05)$ and hepatitis C (RR $2.66,95 \%$ CI 1.33 to $5.35, \mathrm{p}<0.05)$.
Post-transplant outcomes of kidney transplantation in different dialysis modalities

The post-transplant outcomes (ie, death-censored graft failure and all-cause mortality) were compared between the HD and PD groups using Cox proportional hazard analysis (table 4), then significant pretransplant factors (recipient age, sex, dialysis duration and pretransplant diseases (diabetes, stroke and heart failure)) were adjusted in the multivariate analyses. The HR of death-censored graft failure between different dialysis modalities was not significant in univariate analysis, but became significant (HR $1.38,95 \%$ CI 1.03 to 1.84 , $\mathrm{p}<0.05)$ after adjustment. This result implied that great differences existed in recipients with different dialysis modalities, and we had to eliminate these confounding factors before comparison to clarify our result, that is, pretransplant HD contributed to significantly higher risks of allograft failure among surviving recipients. The death-censored graft survival curve between different dialysis modalities was showed in figure 2 , which revealed 
Table 1 Clinical characteristics of kidney-transplant recipients with different dialysis modalities during 1998-2011

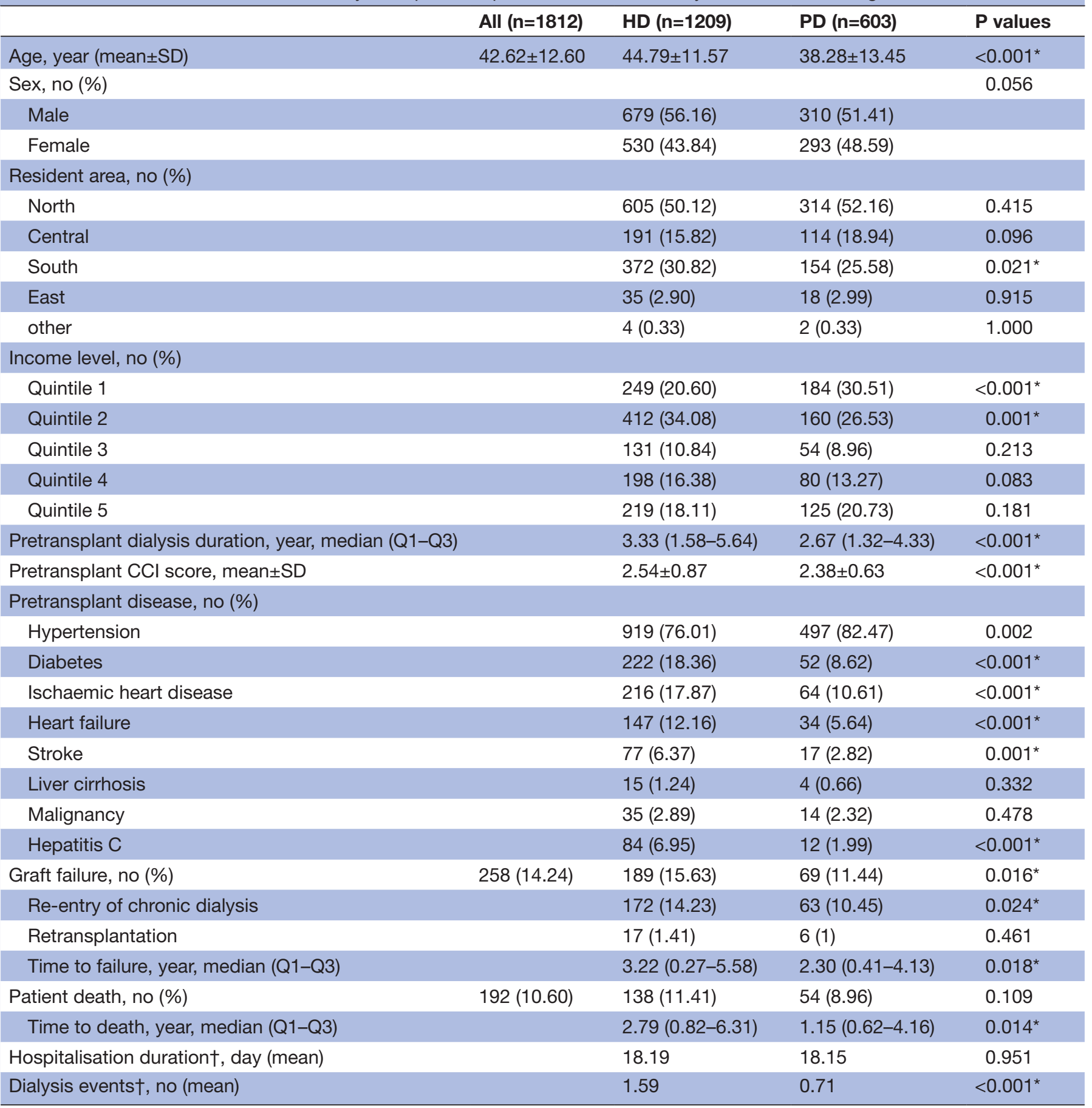

${ }^{*} \mathrm{P}<0.05$.

†The hospitalisation duration and dialysis events during kidney transplantation have been propensity adjusted in log-binomial model by factors including recipient age, sex and pretransplant diseases (diabetes, stroke and heart failure).

$\mathrm{CCl}$, Charlson Comorbidity Index; HD, haemodialysis; PD, peritoneal dialysis.

that the graft survival probability was significantly higher in PD than HD group ( $\mathrm{p}=0.031)$ after 10 years of kidney transplantation during the whole follow-up period. On the other hand, there was no significant difference regarding all-cause mortality between the $\mathrm{HD}$ and $\mathrm{PD}$ groups either in the Cox regression analysis (table 4) or in survival curve (figure 3 ).

\section{DISCUSSION}

In this nationwide cohort study using the NHI database of Taiwan during 1998-2011, we found that kidney-transplant recipients with chronic HD had significantly higher incidences of pretransplant cardiovascular diseases; higher risks of developing post-transplant de novo ischaemic heart disease, tuberculosis and hepatitis 
Table 2 Events during hospitalisation for kidney transplantation between different dialysis modalities after propensity score adjustment $†$

\begin{tabular}{|c|c|c|c|}
\hline $\begin{array}{l}\text { Events } \\
\text { during kidney } \\
\text { transplantation }\end{array}$ & $\begin{array}{l}\text { RR (HD vs } \\
\text { PD) }\end{array}$ & $95 \% \mathrm{Cl}$ & $P$ values \\
\hline $\begin{array}{l}\text { Infection episodes, } \\
\text { no }\end{array}$ & 0.68 & (0.48 to 0.95$)$ & $0.022^{*}$ \\
\hline Bacteraemia & 1.81 & (0.17 to 18.94$)$ & 0.619 \\
\hline Peritonitis & 0.15 & (0.04 to 0.58$)$ & $0.006^{*}$ \\
\hline Pneumonia & 1.38 & (0.48 to 3.94$)$ & 0.547 \\
\hline $\begin{array}{l}\text { Urinary tract } \\
\text { infection }\end{array}$ & 0.66 & (0.45 to 0.96$)$ & $0.029^{*}$ \\
\hline $\begin{array}{l}\text { Vascular } \\
\text { thrombosis }\end{array}$ & 2.76 & (0.32 to 23.56$)$ & 0.354 \\
\hline
\end{tabular}

${ }^{*} \mathrm{P}<0.05$.

†The propensity scores for adjustment included recipient sex, age, dialysis duration and pretransplant diseases (diabetes, stroke and heart failure).

$\ddagger R R$ was expressed as HD as dialysis modality compared with PD.

$H D$, haemodialysis; PD, peritoneal dialysis; $R R$, relative risk.

C after propensity score adjustment; and higher HR of death-censored allograft failure in the multivariate analysis compared with their PD counterpart. The betweengroup difference in post-transplant all-cause mortality was insignificant in the Cox regression analysis. During kidney

\begin{tabular}{|c|c|c|c|}
\hline $\begin{array}{l}\text { New-onset } \\
\text { disease }\end{array}$ & $\begin{array}{l}\text { RR§ (HD vs } \\
\text { PD) }\end{array}$ & $95 \% \mathrm{Cl}$ & $P$ values \\
\hline Hypertension & 1.23 & (0.85 to 1.80$)$ & 0.275 \\
\hline $\begin{array}{l}\text { Ischaemic heart } \\
\text { disease }\end{array}$ & 2.40 & (1.21 to 4.77 ) & $0.013^{*}$ \\
\hline PAOD & 1.11 & (0.38 to 3.24$)$ & 0.843 \\
\hline $\begin{array}{l}\text { Psychiatric } \\
\text { disease }\end{array}$ & 1.46 & (0.87 to 2.46 ) & 0.152 \\
\hline Tuberculosis & 10.23 & (1.35 to 77.47 ) & $0.024^{*}$ \\
\hline Malignancy & 1.03 & (0.67 to 1.57 ) & 0.897 \\
\hline COPD & 1.15 & (0.51 to 2.60$)$ & 0.735 \\
\hline Liver cirrhosis & 2.12 & (0.77 to 5.81$)$ & 0.143 \\
\hline Herpes zoster & 1.09 & (0.91 to 1.31$)$ & 0.358 \\
\hline Hepatitis B & 0.94 & (0.58 to 1.54$)$ & 0.821 \\
\hline Hepatitis C & 2.66 & (1.33 to 5.35 ) & $0.006^{*}$ \\
\hline
\end{tabular}

${ }^{*} \mathrm{P}<0.05$.

†The propensity scores for adjustment included recipient sex, age, dialysis duration and pretransplant diseases (diabetes, stroke and heart failure).

$\ddagger$ New-onset disease was defined as a specific disease code presented in the $\mathrm{NHI}$ database during follow-up period started after 90 days of kidney transplantation until the end of follow-up without a prior history of that disease.

$\S R R$ was expressed as HD as dialysis modality compared with PD. COPD, chronic obstructive pulmonary disease; HD, haemodialysis; $\mathrm{NHI}$, National Health Insurance; PAOD, peripheral arterial occlusive disease; PD, peritoneal dialysis; RR, relative risk. transplantation, recipients with PD had higher risks of developing infection such as peritonitis and UTI, while recipients with HD were associated with more dialysis events and, theoretically, a higher risk of DGF. Moreover, our results indicated that pretransplant HD conferred significantly worse long-term allograft survival after kidney transplantation, possibly explained by the higher cardiovascular risk and impaired immunity in recipients with chronic HD. Therefore, PD might be a better pretransplant dialysis modality than HD for patients with ESRD awaiting kidney transplantation in Taiwan in terms of cost-effectiveness and long-term allograft survival.

Taiwan has been recognised as an epidemic area of kidney disease, and the corresponding health expenditure comprised up to $6 \%$ of total health insurance budget for caring $0.3 \%$ of Taiwanese population receiving dialysis. ${ }^{21}$ The underlying reasons behind the extraordinarily high incidence and prevalence of uraemia and dialysis in Taiwan have often been attributed to global coverage of the dialysis costs for every citizen since 1995, without copayment, in the NHI system; the relatively low mortality rates in patients with uraemia; and the relatively low kidney transplantation rate in Taiwan. ${ }^{22}$ Although PD is used in only $9.2 \%$ of dialysis patients in Taiwan, ${ }^{3}$ one-third of kidney-transplant recipients received pretransplant PD in our cohort, which might be the result of the younger age distribution and better preserved renal function in patients with PD. ${ }^{23}{ }^{24}$ Our results also showed that recipients with chronic HD had significantly higher incidences of pretransplant diabetes, cardiovascular diseases and hepatitis C, and a higher CCI score, which might originate from the pronounced vascular calcification and impaired cellular immunity in patients with chronic HD. ${ }^{25} 26$

The United Network for Organ Sharing defined DGF as the need for at least one dialysis within the first week of kidney transplantation, which is commonly attributed to ischaemia and reperfusion injury. ${ }^{27}$ DGF is associated with increased risk of chronic allograft nephropathy and shortened allograft survival. ${ }^{28}$ Although DGF could not be directly identified in our NHI database, there were significantly more dialysis events in HD patients during hospitalisation for kidney transplantation. Therefore, it is reasonable to deduce that recipients with HD are more likely to have DGF, thus leading to worse allograft survival. This finding is consistent with previous studies reporting that kidney recipients with chronic PD had fewer DGF events, better recovery of renal function and improved graft survival comparing to recipients with $\mathrm{HD} .{ }^{29}$ These observations might be ascribed to the fluid expansion status and better preserved residual renal function in chronic PD patients. ${ }^{22}$

On the other hand, recipients with pretransplant PD had higher risks of developing peritonitis and UTI during hospitalisation for kidney transplantation. Previous studies have shown that PD patients are more frequently complicated with intra-abdominal infection during kidney transplantation, leading to higher risks of early graft failure and worse overall survival. ${ }^{11}$ However, the incidence of 
Table 4 Cox proportional hazard analyses of death-censored graft failure and all-cause mortality after kidney transplantation

\begin{tabular}{|c|c|c|c|c|c|c|}
\hline \multirow[b]{2}{*}{ Variables } & \multicolumn{3}{|c|}{ Univariate analysis } & \multicolumn{3}{|c|}{ Multivariate analysis $†$} \\
\hline & HR & $(95 \% \mathrm{Cl})$ & $P$ values & HR & $(95 \% \mathrm{Cl})$ & $P$ values \\
\hline \multicolumn{7}{|l|}{ Death-censored graft failure } \\
\hline \multicolumn{7}{|l|}{ All-cause mortality } \\
\hline HD as dialysis modality (vs PD) & 1.19 & (0.87 to 1.63$)$ & 0.285 & 0.85 & (0.61 to 1.18$)$ & 0.333 \\
\hline
\end{tabular}

${ }^{*} \mathrm{P}<0.05$.

†Adjusted for recipient sex, age, dialysis duration and pretransplant diseases (diabetes, stroke and heart failure).

$H D$, haemodialysis; PD, peritoneal dialysis.

acute rejection after kidney transplantation is similar in recipients with PD or with HD under modern immunosuppression. ${ }^{30}$ Combining these adverse events during kidney transplantation, recipients with HD might be at a higher risk of developing DGF after kidney transplantation, leading to worse graft survival, while recipients with PD might have more controllable infection risks.

Our analysis showed that recipients with HD had higher risks of developing de novo ischaemic heart disease, tuberculosis and hepatitis $\mathrm{C}$ after kidney transplantation. Vascular calcification, which mainly results from alterations of mineral and bone metabolism during chronic dialysis, is the major cause of enhanced cardiovascular risk in patients with uraemia and is more pronounced in patients receiving $\mathrm{HD} .^{25}$ Although successful kidney transplantation might reduce cardiovascular risks, cardiovascular disease remains the leading cause of graft failure and mortality for patients with a functioning graft. ${ }^{31}$

Further, chronic HD is associated with impaired cellular immunity, mainly due to a deficiency in the interaction of T-cells with the antigen-presenting cells ${ }^{24}$; this might be responsible for the higher incidences of tuberculosis and hepatitis C in recipients with $\mathrm{HD}$ in our results. Impaired immunity in HD patients could exacerbate chance infections, such as tuberculosis, hepatitis C, cytomegalovirus and BK polyomavirus reactivation after transplantation, thus imposing serious threats of allograft loss and patient death. ${ }^{32-34}$

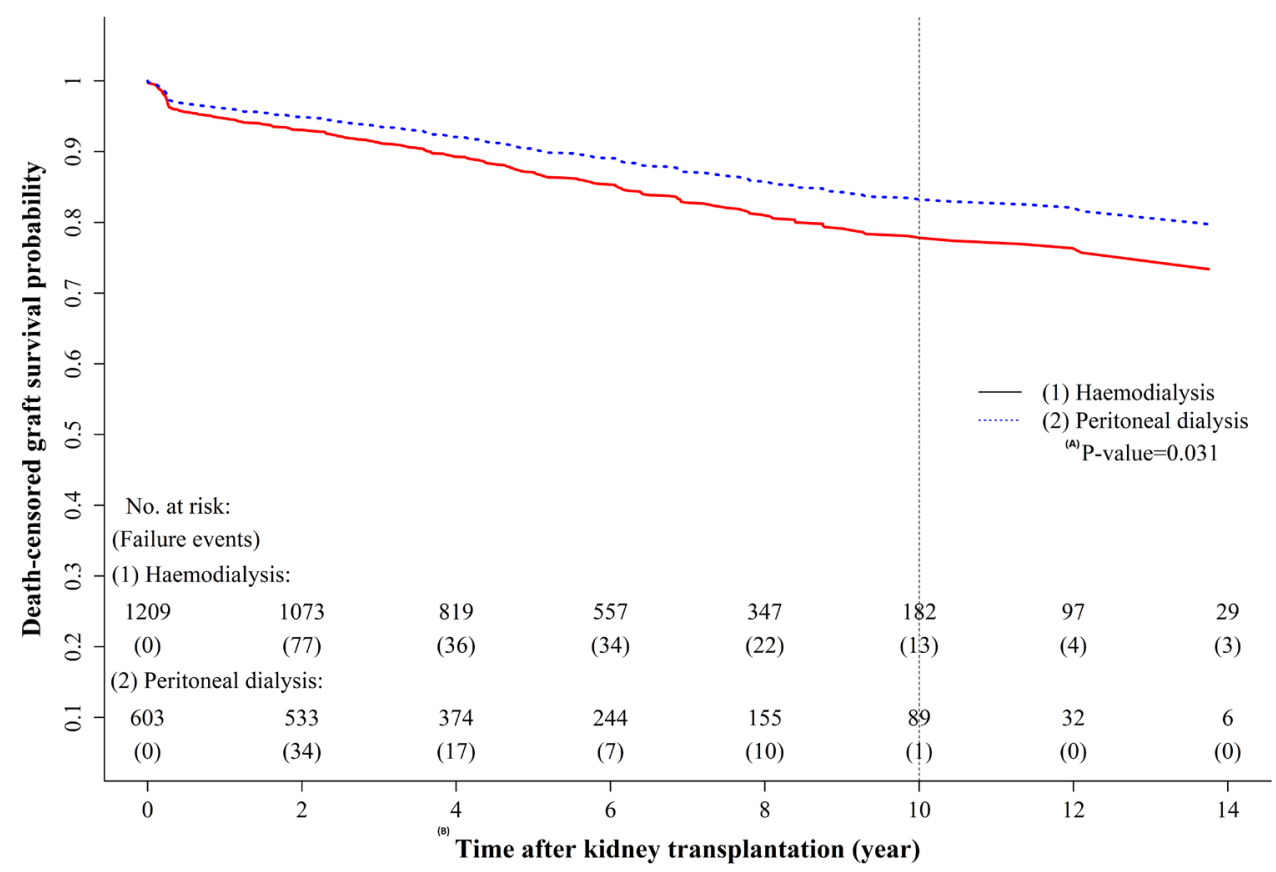

Figure 2 Survival curves of the adjusted Cox proportional hazard model for death-censored graft survival according to the different dialysis modalities. (A) Recipients with peritoneal dialysis had significantly higher death-censored graft survival than recipients with haemodialysis after 10 years of kidney transplantation $(p=0.031)$. (B) The whole follow-up period was 14 years (from 1998 to 2011). 


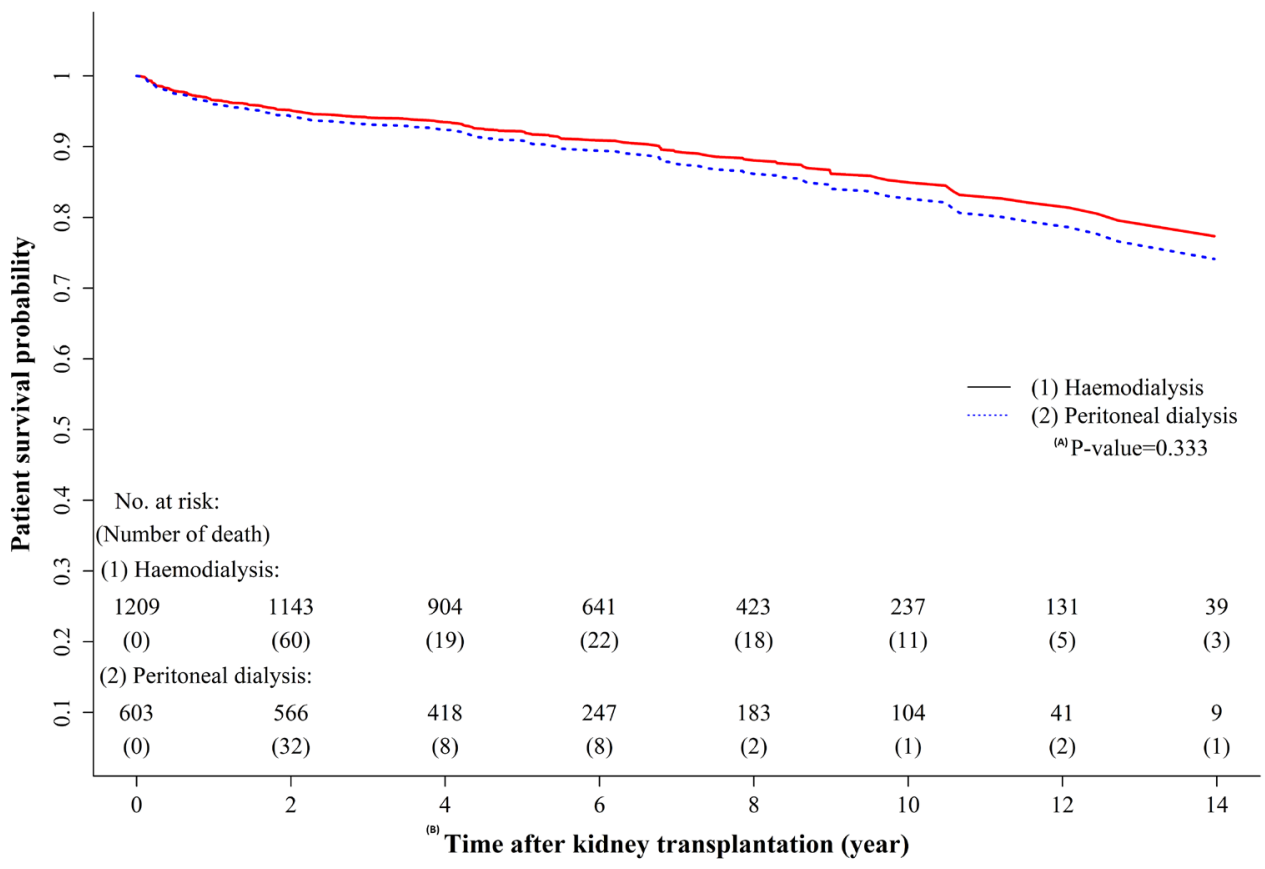

Figure 3 Survival curves of the adjusted Cox proportional hazard model for overall survival according to the different dialysis modalities. (A) There were no significant differences in post-transplant patient survival between recipients with peritoneal dialysis and recipients with haemodialysis ( $p=0.333$ ). (B)The whole follow-up period was 14 years (from 1998 to 2011).

The reported recipient factors affecting the long-term outcomes of kidney transplantation include the recipient age, sex, human leukocyte antigen (HLA) matching, dialysis duration, cardiovascular comorbidities and dialysis modality. ${ }^{85}$ Increasing dialysis exposure is associated with higher risks for developing cross-reactive antidonor T-cell immunity and cardiovascular diseases, thus leading to worse long-term outcomes in patients with longer HD vintage. ${ }^{36}{ }^{37}$ In our cohort, recipients with HD had significantly longer pretransplant dialysis duration compared with the PD group, thereby consequently conferring a greater risk of allograft failure after kidney transplantation.

Regarding the impact of the pretransplant dialysis modality on kidney transplantation outcomes, the available evidences derived from observational studies are inconsistent and conflicting. ${ }^{38-42}$ Table 5 summarises these previous studies and appraises their qualities with the Newcastle-Ottawa Scale for observational studies as well as the Preferred Reporting Items for Systematic Reviews and Meta-Analyses tool for systematic review. ${ }^{434}$ These contradictory results may originate from different study design, country, population, follow-up duration, era and the statistic method used to address confounding factors. A recent review concluded that PD conferred a lower incidence of DGF and better 5-year patient survival, but not graft survival, and recommended PD as the better choice of pretransplant dialysis modality. ${ }^{13}$ Taken together of these studies, we might be able to summarise that pretransplant HD confer worse long-term outcomes after kidney transplantation, which might be ascribed to impaired immunity and higher cardiovascular risks in chronic HD patients. However, the influence of the dialysis modality on the kidney transplantation outcomes might be only modest, especially under modern sophisticated transplantation care.

\section{LIMITATIONS}

This nationwide cohort study using the NHI database has some inherent limitations. First, while the NHI database contains deidentified patient information encrypted with ICD codes, there are no available clinical donor or recipient details such as living or deceased donor, graft condition, DGF, ischaemia time, panel reactive antibody (PRA) level or sensitisation, renal function (such as glomerular filtration rate), HLA mismatch, ABO incompatibility, acute rejection and graft failure, etc. Therefore, we could not estimate the influences of these factors on post-transplant outcomes and make corresponding adjustments. Second, the great differences in clinical and demographic features between HD and PD patients might strongly confound the outcomes and undermine our comparisons. Even though we had excluded unsuitable populations and adjusted significant pretransplant features in the propensity-adjusted log-binomial model 
Table 5 Review of studies evaluating impact of dialysis modality on kidney-transplant outcomes

\begin{tabular}{|c|c|c|c|c|c|c|}
\hline $\begin{array}{l}\text { Authors (year), }{ }^{*} \\
\text { country }\end{array}$ & Study design & Patient no & Follow-up period & Post-transplant outcomes & Favour & Quality† \\
\hline $\begin{array}{l}\text { Goldfarb-Rumyantzev } \\
\text { et al (2005), }{ }^{41} \text { USA }\end{array}$ & $\begin{array}{l}\text { Cohort, retrospective } \\
\text { database }\end{array}$ & $\begin{array}{l}92844 \text { patients from USRDS } \\
\text { database }\end{array}$ & $\begin{array}{l}\text { 10years } \\
\text { (during 1990-1999) }\end{array}$ & $\begin{array}{l}\text { PD was associated with shorter } \\
\text { time on dialysis, better graft and } \\
\text { patient survival }\end{array}$ & PD & Good \\
\hline $\begin{array}{l}\text { Molnar et al (2011), } \\
\text { USA }\end{array}$ & $\begin{array}{l}\text { Cohort, retrospective } \\
\text { database }\end{array}$ & $\begin{array}{l}14508 \text { recipients } \\
\text { (HD:12416, PD:2092) }\end{array}$ & $\begin{array}{l}6 \text { years } \\
\text { (during 2001-2006) }\end{array}$ & $\begin{array}{l}\text { PD with lower mortality rate, but } \\
\text { no differences in DGF or death- } \\
\text { censored graft survival after } \\
\text { adjustment }\end{array}$ & PD & Fair \\
\hline $\begin{array}{l}\text { Kramer et al (2012), } \\
\text { the Netherlands }\end{array}$ & $\begin{array}{l}\text { Cohort, retrospective } \\
\text { database }\end{array}$ & $\begin{array}{l}29088 \text { adult recipients from } 16 \\
\text { European renal registries }\end{array}$ & $\begin{array}{l}\text { Median 5years } \\
\text { (during 1999-2008) }\end{array}$ & $\begin{array}{l}\text { PD was associated with better } \\
\text { patient and graft survivals, but no } \\
\text { longer significant after instrumental } \\
\text { variable analysis }\end{array}$ & Non & Good \\
\hline $\begin{array}{l}\text { López-Oliva et al } \\
\text { (2013), }{ }^{12} \text { Spain }\end{array}$ & $\begin{array}{l}\text { Cohort, } \\
\text { retrospective single- } \\
\text { centre }\end{array}$ & $\begin{array}{l}236 \text { recipients (HD: } 118, \\
\text { PD:118) }\end{array}$ & $\begin{array}{l}\text { Median 8.5years } \\
\text { (during 1990-2002) }\end{array}$ & $\begin{array}{l}\text { PD has better long-term patient } \\
\text { survival, but not graft survival in } \\
\text { the multivariate analysis }\end{array}$ & PD & Fair \\
\hline $\begin{array}{l}\text { Dipalma et al (2016), }{ }^{14} \\
\text { Spain }\end{array}$ & $\begin{array}{l}\text { Cohort, retrospective } \\
\text { single centre }\end{array}$ & $\begin{array}{l}180 \text { donor-matched recipients } \\
\text { (HD:80, PD:80) }\end{array}$ & $\begin{array}{l}\text { Median } 73 \text { months } \\
\text { (during 1990-2007) }\end{array}$ & $\begin{array}{l}\text { No significant difference in death- } \\
\text { censored graft survival and patient } \\
\text { survival after propensity-score } \\
\text { adjustment }\end{array}$ & Non & Good \\
\hline $\begin{array}{l}\text { Tang et al (2016), }{ }^{13} \\
\text { China }\end{array}$ & Meta-analysis & $\begin{array}{l}12 \text { studies, excluded children, } \\
\text { sample }<100 \text { pts }\end{array}$ & - & $\begin{array}{l}\text { PD conferred less DGF, better } \\
5 \text {-year patient survival, but not } \\
\text { graft survival }\end{array}$ & PD & Fair \\
\hline
\end{tabular}

*The references are listed in the order of published year.

†Quality assessments were based on the Newcastle-Ottawa Scale for observational cohort studies and the Preferred Reporting Items for Systematic Reviews and Meta-Analyses tool for systemic review/meta-analysis. All studies were rated as 'good, fair or poor' according to fulfilment of applied assessment checklist. DGF, delayed graft function; HD, haemodialysis; PD, peritoneal dialysis; USRDS, United States Renal Data System.

and multivariate analyses, there might be other unidentified covariates (ie, residual selection bias) that could potentially confound the post-transplant outcomes. Third, the true cause of death is inaccessible in our NHI database, so we could not distinguish death with functioning graft, death with graft failure or cardiovascular death. Fourth, coding errors or miscoding might exist in the large nationwide database, even though the accuracy of our NHI database has been reported in previous studies. ${ }^{15}$ Finally, our study period spanned from 1998 to 2011. During these years, the medical therapies for dialysis patients and interventions for kidney-transplant recipients have changed substantially, so our results might be confounded by this era effect.

Despite these limitations, this study has several strengths. First, this is the first nationwide population-based cohort study to demonstrate that pretransplant HD contributed to higher risks of post-transplant de novo diseases and allograft failure after kidney transplantation. The evidence-based comparison of pretransplant dialysis modality on post-transplant outcomes provides valuable information for dialysis patients awaiting kidney transplantation, especially in Asian population. Second, we used a nationwide database that covers more than $99.6 \%$ of the Taiwanese population, and its representativeness and integrity have been previously validated. Third, our study had a relatively large number of recipients and a long follow-up duration compared with other studies, making our results more convincing.

\section{CONCLUSIONS}

In conclusion, our nationwide cohort study using the NHI database of Taiwan showed that kidney-transplant recipients with pretransplant chronic HD were associated with more dialysis events during kidney transplantation, and thereby a higher possibility of DGF. Besides, kidney recipients with chronic HD had significantly higher risks of developing post-transplant de novo ischaemic heart disease, tuberculosis and hepatitis $\mathrm{C}$ after propensity score adjustment; and had a higher risk of long-term death-censored graft failure in the multivariate analysis after adjustment.

Acknowledgements This study was based on data from the NHI research database provided by the Bureau of NHI, Department of Health and managed by the National Health Research Institutes. The interpretations and conclusions contained herein do not represent the views of the Bureau of the NHI, Department of Health or National Health Research Institutes.

Contributors All authors made contributions to the paper and authorised the submission. H-TL, F-CL and H-PY contributed clinical interpretation of results and drafted the manuscript. H-TL and F-CL designed the study, supported data analyses and interpretation and supported manuscript preparation. J-RL provided data management, analyses and data interpretation. S-TP contributed clinical interpretation. All authors contributed to manuscript preparation and critical revision. 
Funding This work was partially supported by grants from the National Science Council of Taiwan (project 103-2314-B-182A-070-MY2, 103-2314-B-182043-MY2, and 105-2314-B-182A-137-MY3) and the Chang Gung Memorial Hospital (project CMRPG3F1011, CMRPG3D1671 and CORPG3E0131).

Competing interests None declared.

Patient consent Not required.

Ethics approval The present study was evaluated and approved by the Institutional Review Board of Chang Gung Medical Foundation, Taiwan (approval number: 104-6697B).

Provenance and peer review Not commissioned; externally peer reviewed.

Data sharing statement No additional data are available.

Open Access This is an Open Access article distributed in accordance with the Creative Commons Attribution Non Commercial (CC BY-NC 4.0) license, which permits others to distribute, remix, adapt, build upon this work non-commercially, and license their derivative works on different terms, provided the original work is properly cited and the use is non-commercial. See: http://creativecommons.org/ licenses/by-nc/4.0/

(c) Article author(s) (or their employer(s) unless otherwise stated in the text of the article) 2018. All rights reserved. No commercial use is permitted unless otherwise expressly granted.

\section{REFERENCES}

1. Goldfarb-Rumyantzev A, Hurdle JF, Scandling J, et al. Duration of end-stage renal disease and kidney transplant outcome. Nephrol Dial Transplant 2005;20:167-75

2. Amaral S, Sayed BA, Kutner N, et al. Preemptive kidney transplantation is associated with survival benefits among pediatric patients with end-stage renal disease. Kidney Int 2016;90:1100-8.

3. Saran R, Robinson B, Abbott KC, et al. US Renal data system 2016 annual data report: epidemiology of kidney disease in the United States. Am J Kidney Dis 2017;69(Suppl 1):A7-8.

4. Klarenbach SW, Tonelli M, Chui B, et al. Economic evaluation of dialysis therapies. Nat Rev Nephrol 2014;10:644-52.

5. Kwong VW-K, Li PK-T. Peritoneal dialysis in Asia. Kidney Dis 2015;1:147-56.

6. Chang YT, Hwang JS, Hung SY, et al. Cost-effectiveness of hemodialysis and peritoneal dialysis: a national cohort study with 14 years follow-up and matched for comorbidities and propensity score. Sci Rep 2016;6:30266.

7. Mehrotra R, Devuyst O, Davies SJ, et al. The current state of peritoneal dialysis. J Am Soc Nephrol 2016;27:3238-52.

8. Legendre C, Canaud G, Martinez F. Factors influencing long-term outcome after kidney transplantation. Transp/ Int 2014;27:19-27.

9. El-Zoghby ZM, Stegall MD, Lager DJ, et al. Identifying specific causes of kidney allograft loss. Am J Transplant 2009;9:527-35.

10. Wu DA, Robb ML, Watson CJE, et al. Barriers to living donor kidney transplantation in the United Kingdom: a national observational study. Nephrol Dial Transplant 2017;32:890-900.

11. Martins LS, Malheiro J, Pedroso S, et al. Pancreas-kidney transplantation: impact of dialysis modality on the outcome. Transpl Int 2015;28:972-9.

12. López-Oliva MO, Rivas B, Pérez-Fernández E, et al. Pretransplant peritoneal dialysis relative to hemodialysis improves long-term survival of kidney transplant patients: a single-center observational study. Int Urol Nephrol 2014;46:825-32.

13. Tang M, Li T, Liu H. A comparison of transplant outcomes in peritoneal and hemodialysis patients: a meta-analysis. Blood Purif 2016;42:170-6.

14. Dipalma T, Fernández-Ruiz M, Praga M, et al. Pre-transplant dialysis modality does not influence short- or long-term outcome in kidney transplant recipients: analysis of paired kidneys from the same deceased donor. Clin Transplant 2016;30:1097-107.

15. Sung SF, Hsieh CY, Lin HJ, et al. Validation of algorithms to identify stroke risk factors in patients with acute ischemic stroke, transient ischemic attack, or intracerebral hemorrhage in an administrative claims database. Int J Cardiol 2016;215:277-82.

16. Rigoni M, Torri E, Nollo G, et al. Survival and time-to-transplantation of peritoneal dialysis versus hemodialysis for end-stage renal disease patients: competing-risks regression model in a single Italian center experience. J Nephrol 2017;30:441-7.
17. Noordzij M, Leffondré K, van Stralen KJ, et al. When do we need competing risks methods for survival analysis in nephrology? Nephrol Dial Transplant 2013;28:2670-7.

18. Deb S, Austin PC, Tu JV, et al. A review of propensity-score methods and their use in cardiovascular research. Can J Cardiol 2016;32:259-65.

19. Branch-Elliman W, Ripollone JE, O'Brien WJ, et al. Risk of surgical site infection, acute kidney injury, and Clostridium difficile infection following antibiotic prophylaxis with vancomycin plus a beta-lactam versus either drug alone: a national propensity-score-adjusted retrospective cohort study. PLoS Med 2017;14:e1002340.

20. Ali MS, Groenwold RH, Belitser SV, et al. Reporting of covariate selection and balance assessment in propensity score analysis is suboptimal: a systematic review. J Clin Epidemiol 2015;68:122-31.

21. Lin YC, Lin YC, Kao CC, et al. Health policies on dialysis modality selection: a nationwide population cohort study. BMJ Open 2017;7:e013007.

22. Hwang SJ, Tsai JC, Chen HC. Epidemiology, impact and preventive care of chronic kidney disease in Taiwan. Nephrology 2010;15(Suppl 2):3-9.

23. Fuquay R, Teitelbaum I. Transplant outcomes and dialysis modality. Contrib Nephrol 2012;178:251-7.

24. Tsai TC, Chen YC, Lo CW, et al. Incidence and renal survival of ESRD in the young Taiwanese population. Clin J Am Soc Nephrol 2014;9:302-9.

25. D'Marco L, Bellasi A, Mazzaferro S, et al. Vascular calcification, bone and mineral metabolism after kidney transplantation. World $J$ Transplant 2015;5:222-30.

26. Eleftheriadis T, Antoniadi G, Liakopoulos V, et al. Disturbances of acquired immunity in hemodialysis patients. Semin Dial 2007;20:440-51.

27. Nashan B, Abbud-Filho M, Citterio F. Prediction, prevention, and management of delayed graft function: where are we now? Clin Transplant 2016;30:1198-208.

28. Schröppel B, Legendre C. Delayed kidney graft function: from mechanism to translation. Kidney Int 2014;86:251-8.

29. Fontana I, Santori G, Ginevri F, et al. Impact of pretransplant dialysis on early graft function in pediatric kidney recipients. Transpl Int 2005;18:785-93.

30. Lobbedez T, Lecouf A, Abbadie O, et al. Peritoneal dialysis and renal transplantation. Contrib Nephrol 2009;163:250-6.

31. Stoumpos S, Jardine AG, Mark PB. Cardiovascular morbidity and mortality after kidney transplantation. Transpl Int 2015;28:10-21.

32. Chen $\mathrm{CH}, \mathrm{Wu} \mathrm{MJ}$, Lin $\mathrm{CH}$, et al. Comparison of tuberculosis infection rates in a national database of renal transplant patients with data from a single center in Taiwan. Transplant Proc 2014;46:588-91.

33. Tsai HI, Yu HP, Hp Y. A review of nationwide population study of organ transplantation in Taiwan. Acta Anaesthesiol Taiwan 2016;54:70-4.

34. Lee PC, Chiang YJ, Chen ST. Deceased donor kidney transplantation in Taiwan in 2015. Clin Transpl 2014:55-9.

35. Augustine JJ, Poggio ED, Clemente M, et al. Hemodialysis vintage, black ethnicity, and pretransplantation antidonor cellular immunity in kidney transplant recipients. J Am Soc Nephrol 2007;18:1602-6.

36. Helanterä I, Salmela K, Kyllönen L, et al. Pretransplant dialysis duration and risk of death after kidney transplantation in the current era. Transplantation 2014;98:458-64.

37. Chen PD, Tsai MK, Lee CY, et al. Gender differences in renal transplant graft survival. J Formos Med Assoc 2013;112:783-8.

38. Couchoud C, Bolignano D, Nistor I, et al. Dialysis modality choice in diabetic patients with end-stage kidney disease: a systematic review of the available evidence. Nephrol Dial Transplant 2015;30:310-20.

39. Kramer A, Jager KJ, Fogarty DG, et al. Association between pretransplant dialysis modality and patient and graft survival after kidney transplantation. Nephrol Dial Transplant 2012;27:4473-80.

40. Molnar MZ, Mehrotra R, Duong U, et al. Dialysis modality and outcomes in kidney transplant recipients. Clin J Am Soc Nephrol 2012;7:332-41.

41. Goldfarb-Rumyantzev AS, Hurdle JF, Scandling JD, et al. The role of pretransplantation renal replacement therapy modality in kidney allograft and recipient survival. Am J Kidney Dis 2005;46:537-49.

42. Schwenger V, Döhler B, Morath $\mathrm{C}$, et al. The role of pretransplant dialysis modality on renal allograft outcome. Nephrol Dial Transplant 2011;26:3761-6.

43. Wells G, Shea B, O' Connell D, et al. The Newcastle-Ottawa scale (NOS) for assessing the quality of nonrandomised studies in metaanalyses. Ottawa, ON: Ottawa Hospital Research Institute.

44. Moher D, Liberati A, Tetzlaff J, et al. Preferred reporting items for systematic reviews and meta-analyses: the PRISMA statement. PLOS Med 2009;6:e1000097. 